\title{
New guidelines on primary PCI for patients with STEMI: changing insights
}

\author{
E.E. van der Wall
}

Published online: 8 December 2015

(C) The Author(s) 2015. This article is published with open access at Springerlink.com

Recently, the American College of Cardiology, American Heart Association, and Society for Cardiovascular Angiography and Interventions (ACC/AHA/SCAI) have updated their guidelines on primary percutaneous coronary intervention (PCI) for patients with ST-segment-elevation myocardial infarction (STEMI). These organisations have made several remarkable changes from previous recommendations. The new guidelines were published in the Journal of the American College of Cardiology in October 2015 [1].

The background for the 2015 focused update was novel findings from clinical trials presented at the major cardiology congresses from 2013 to 2015 and new information from other peer-reviewed studies published up to August 2015. These recent studies were thoroughly reviewed by the 2011 PCI and 2013 STEMI Guideline Writing Committees and the Task Force to identify trials and other crucial data that might affect guideline recommendations. This information was considered important enough to prompt updated recommendations and was included in evidence tables in the Online Data Supplement to be found on:

http://jaccjacc.acc.org/Clinical_Document/2015 Focused_Update_on_Primary_PCI_in_STEMI_Data_Supplements.pdf)

The Classes of Recommendation and Levels of Evidence were derived independently of one another according to established criteria. Five different classes were distinguished: Class I (Strong), IIa (Moderate), IIb (Weak), III (No benefit, moderate), and Class III (Harm, strong). Also,

E.E. van der Wall $(\bowtie)$

Netherlands Society of Cardiology/Holland Heart House,

Moreelsepark 1,

3511 EP Utrecht, The Netherlands

e-mail: eevanderwall@hotmail.com five levels of evidence were used: Level A, B-R (randomised), B-NR (non-randomised), C-LD (limited data), and Level C-EO (expert opinion).

The scope of the 2015 focused update was restricted to two main areas: 1) multi-vessel PCI, and 2) thrombus aspiration in patients with STEMI undergoing primary PCI.

\section{1) Culprit artery-only PCI versus multi-vessel PCI}

The 2013 recommendation was Class III (Harm), indicating that PCI should not be performed in a non-infarct artery at the time of primary PCI in patients with STEMI who are haemodynamically stable (Level of Evidence B).

The new recommendation of 2015 is now Class IIb, demonstrating that PCI of a non-infarct artery may be considered in selected patients with STEMI and multi-vessel disease who are haemodynamically stable, either at the time of primary PCI or as a planned staged procedure (Level of Evidence B-R). It was commented that the 2015 recommendation changed from Class III (Harm) to Class IIb and expanded the time frame in which multi-vessel PCI could be performed.

\section{2) Aspiration thrombectomy}

Recommendations of 2011/2013 were Class IIa, indicating that manual aspiration thrombectomy is reasonable for patients undergoing primary PCI (Level of Evidence B).

The new recommendation of 2015 is Class IIb, showing that the usefulness of selective and bailout aspiration thrombectomy in patients undergoing primary $\mathrm{PCI}$ is not well established (Level of Evidence C-LD). The recommendation of 2015 for routine aspiration thrombectomy is now Class III (No benefit), indicating that routine aspiration thrombectomy before primary PCI is not useful (Level of Evidence A). 
It was commented that the 2015 recommendation changed from Class IIa to Class IIb for selective and bailout aspiration thrombectomy before PCI and that routine aspiration thrombectomy before primary PCI is not useful.

In summary, the 2015 report has significantly updated the $2011 \mathrm{ACC} / \mathrm{AHA} / \mathrm{SCAI}$ Guideline for PCI and the 2013 ACC/AHA Guideline for the Management of STEMI. The 2015 focused update did address two major issues: 1) the setting of primary PCI for multi-vessel PCI, and 2) the usefulness of thrombus aspiration. Regarding multi-vessel PCI, new evidence from recent clinical trials clearly showed that treating other non-culprit stenosed coronary arteries may be safe and beneficial in selected patients with multi-vessel disease. The 2015 focused update states that treating the non-culprit stenosed arteries with a stent may be considered in patients with STEMI who are haemodynamically stable at the time of the primary PCI. Concerning the usefulness of thrombus aspiration, the prior Class IIa recommendation for aspiration thrombectomy was changed to Class IIb in 2015. There are at present insufficient data to assess the potential benefit of a strategy of selective or bailout aspiration thrombectomy. The 2015 focused update states that routine aspiration thrombectomy before primary PCI is currently not recommended.

The above-mentioned new recommendations may also have consequences for newly planned guidelines of the European Society of Cardiology (ESC) on STEMI. In 2012 the ESC STEMI guidelines reported: 1) that primary PCI should be limited to the culprit vessel with the exception of cardiogenic shock and persistent ischaemia after PCI of the supposed culprit lesion (Class IIa, Level B), and 2) that routine thrombus aspiration should be considered (Class IIa, Level B) [2]. The updated ESC STEMI guidelines are among the new publications scheduled in 2017.

What can be learned from new recommendations and guidelines? Generally speaking, according to the definition of the ESC, guidelines aim to present all the relevant evidence on a particular clinical issue in order to help physicians to weigh the benefits and risks of a particular diagnostic or therapeutic procedure [3-6]. They should be helpful in everyday clinical medical decision-making. More importantly, guidelines should be updated every 4 to 5 years in order to offer the patient the best possible treatment based on the most actual findings [7-11]. An updated guideline, however, does not necessarily invalidate the previous guideline; a new guideline predominantly reflects the progress in science and its ensuing change of views over time. New guidelines are built on older guidelines based on moving insights inspired by advanced research [12-14]. In itself, each guideline represents the level of science at that particular point in time. Fortunately, progress in research teaches us that the level of science moves forward implying that guidelines have to be regularly revisited, primarily in the interest of optimal diagnosis and treatment of the patient [15-18]. In this respect, the 2015 focused update on primary PCI for patients with STEMI offers an illustrative example of changing insights based on novel findings [1].

Open Access This article is distributed under the terms of the Creative Commons Attribution License which permits any use, distribution, and reproduction in any medium, provided the original author(s) and source are credited.

\section{References}

1. Levine GN, O'Gara PT, Bates ER, et al. 2015 ACC/AHA/SCAI Focused Update on Primary Percutaneous Coronary Intervention for Patients With ST-Elevation Myocardial Infarction: an Update of the 2011 ACCF/AHA/SCAI Guideline for Percutaneous Coronary Intervention and the $2013 \mathrm{ACCF} / \mathrm{AHA}$ Guideline for the Management of ST-Elevation Myocardial Infarction: a Report of the American College of Cardiology/American Heart Association Task Force on Clinical Practice Guidelines and the Society for Cardiovascular Angiography and Interventions. J Am Coll Cardiol. 2015. doi:10.1016/j.jacc.2015.10.005. (pii: S0735-1097(15):06797-2).

2. Steg PG, James SK, Atar D, et al. Task Force on the management of ST-segment elevation acute myocardial infarction of the European Society of Cardiology (ESC). ESC Guidelines for the management of acute myocardial infarction in patients presenting with ST-segment elevation. Eur Heart J. 2012;33:2569-619. doi:10.1093/eurheartj/ehs215.

3. Thygesen K, Alpert JS, White HD, et al. Joint ESC/ACCF/AHA/ WHF Task Force for the Redefinition of Myocardial Infarction. Universal definition of myocardial infarction. Circulation. 2007;116:2634-53.

4. Kikkert WJ, Piek JJ, Winter RJ de, Peters RJ, Henriques JP. Guideline adherence for antithrombotic therapy in acute coronary syndrome: an overview in Dutch hospitals. Neth Heart J. 2010;18:291-9.

5. Heestermans AA, Hermanides RS, Gosselink AT, et al. A comparison between upfront high-dose tirofiban versus provisional use in the real-world of non-selected STEMI patients undergoing primary PCI: insights from the Zwolle acute myocardial infarction registry. Neth Heart J. 2010;18:592-7.

6. Hermanides RS, Ottervanger JP, Dambrink JH, et al. Zwolle Myocardial Infarction Study Group. Suboptimal anticoagulation with pre-hospital heparin in ST-elevation myocardial infarction. Thromb Haemost. 2011;106:636-40. doi:10.1160/TH11-04-0257.

7. Verheugt FW. Trials, registries and guidelines for non-ST-elevation acute coronary syndromes. Neth Heart J. 2014;22:52-4. doi:10.1007/s12471-013-0495-7.

8. Luermans JG, Mafi Rad M, Vernooy K. A call for re-evaluation of the guidelines for prophylactic ICD implantation. Neth Heart J. 2014;22:429-30. doi:10.1007/s12471-014-0591-3.

9. Puymirat E, Caudron J, Steg PG, et al. FAST-MI investigators. Prognostic impact of non-compliance with guidelines-recommended times to reperfusion therapy in ST-elevation myocardial infarction. The FAST-MI 2010 registry. Eur Heart J Acute Cardiovasc Care. 2015. doi:10.1177/2048872615610893. (pii: 2048872615610893).

10. Kristensen SD, Laut KG, Fajadet J, et al. European Association for Percutaneous Cardiovascular Interventions. Reperfusion therapy for ST elevation acute myocardial infarction 2010/2011: current status in 37 ESC countries. Eur Heart J. 2014;35:1957-70. doi:10.1093/eurheartj/eht529. 
11. Yetgin T, Linden MM van der, Vries AG de, CCR Study Investigators, et al. Adoption of prasugrel into routine practice: rationale and design of the Rijnmond Collective Cardiology Research (CCR) study in percutaneous coronary intervention for acute coronary syndromes. Neth Heart J. 2014;22:55-61. doi:10.1007/ s12471-013-0472-1.

12. Wall EE van der. New ESC guidelines on hypertrophic cardiomyopathy: new insights in invasive treatment? Neth Heart J. 2015;23:1-3. doi:10.1007/s12471-014-0636-7.

13. Verheugt FW. Anticoagulation in patients with mechanical heart valves: follow the guidelines! Neth Heart J. 2015;23:109-10. doi:10.1007/s12471-014-0642-9.

14. Tra J, Wulp I van der, Appelman Y, Bruijne MC de, Wagner C. Adherence to guidelines for the prescription of secondary prevention medication at hospital discharge after acute coronary syndrome: a multicentre study. Neth Heart J. 2015;23:214-21. doi:10.1007/ s12471-015-0664-y.
15. Piek JJ, Claessen BE, Davies JE, Escaned J. Physiology-guided myocardial revascularisation in complex multivessel coronary artery disease: beyond the 2014 ESC/EACTS guidelines on myocardial revascularisation. Open Heart. 2015;2:e00308. doi:10.1136/ openhrt-2015-000308.

16. Claessen BE, Schaaf R van der, Cate TT, Piek JJ. A Dutch perspective on the ESC/EACTS guidelines on myocardial revascularisation. Neth Heart J. 2015;23:290-1. doi:10.1007/ s12471-015-0685-6.

17. Vos GJ, Bennaghmouch N, Qaderdan K, Ten Berg JM. Management of the patient with an acute coronary syndrome using oral anticoagulation. Neth Heart J. 2015;23:407-14. doi:10.1007/ s12471-015-0727-0.

18. Rasoul S, Ommen V van, Vainer J, et al. Multivessel revascularisation versus infarct-related artery only revascularisation during the index primary PCI in STEMI patients with multivessel disease: a meta-analysis. Neth Heart J. 2015;23:224-31. doi:10.1007/ s12471-015-0674-9. 